\title{
el examen de la resistencia del hormigón en la constructión
}

Prof. Dr. Ing. KARLHANS WESCHE, AACHEN

Betonstein-Zeitung, $n^{\circ} 6,1967$, pägs. 267-277

Las prescripciones de la construcción en los distintos países exigen, en general, que en las obras de hormigón y hormigón armado se fabriquen probetas (cubos, cilindros o prismas) y que transcurrido cierto tiempo se examinen en cuanto a su resistencia; en la mayoría de los casos son rotas a compresión al cabo de 28 días. Las probetas deben almacenarse hasta su ensayo a temperatura constante y en las condiciones de humedad prescritas (conservación en agua, en ambiente húmedo, o en ambiente húmedo al principio y luego al aire ambiente).

Es decir, que se trata siempre de un ensayo de calidad bajo condiciones normalizadas. Las resistencias determinadas de este modo no son idénticas, en general, a las reales del hormigón en la construcción, principalmente como consecuencia de las diferentes condiciones de fraguado y endurecimiento. $\mathrm{Si}$, por el contrario, se ensaya la resistencia del hormigón en obra, se trata solamente de un ensayo que frecuentemente no se toma en consideración, en caso de litigio. Así, por ejemplo, no puede demostrarse la calidad del hormigón en la obra con una edad de 28 días en las estaciones frías del año; con una fórmula adecuada se debe calcular la edad correspondiente del hormigón, para una conservación a $20^{\circ} \mathrm{C}$.

En el ensayo de calidad, el número de probetas exigidas es, en general, demasiado pequeño, para poder juzgar con seguridad la calidad del hormigón estadísticamente. Con frecuencia, el hormigón de obra y el de la probeta se han endurecido de forma distinta y a menudo no son ni siquiera idénticos. Finalmente, en muchos casos, no se alcanza la calidad exigida para el hormigón. $Y$ puesto que por motivos técnicos y económicos no es posible tomar un número suficiente de probetas en la obra y destruirlas en el ensayo, se deben de utilizar en estos casos procedimientos de ensayo no destructivos para determinar la calidad de un hormigón.

\section{Comparación de los métodos de ensayo no destructivos}

Para el ensayo del hormigón por métodos no destructivos, en Alemania se emplean tres procedimientos, cuyo principio se representa en la figura 1. Siguiendo el orden marcado por la frecuencia de su utilización son:

- la medición del rebote con el martillo;

- la medición de la huella de la bola mediante el martillo correspondiente;

- la medición del registro de sonido con el aparato ultrasónico, y con ello el cálculo de la velocidad de aquél. 
Los dos primeros procedimientos están normalizados en DIN 4240 (1). En los dos primeros procedimientos de choque, una masa metálica golpea la superficie del hormigón, siendo éste acelerado bajo el efecto de resortes. La energía del choque es absorbida, en parte, por una deformación permanente de la superficie del hormigón y, el resto, en el rebote del cuerpo que golpea. En el ensayo sónico se emite un impulso a través del hormigón y se mide el tiempo transcurrido entre la emisión y la recepción.

En el caso de estampado de la bola es examinada la deformación plástica del cemento; con la medición del rebote y con el tiempo transcurrido para el sonido en su recorrido se ensaya, por el contrario, el comportamiento elástico (2). Es decir, que el primer método se diferencia fundamentalmente de los otros dos. Sin embargo, es común, para todos, el que la resistencia queda determinada indirectamente, relacionando la deformación con la dureza, hechos que difícilmente pueden relacionarse entre sí.

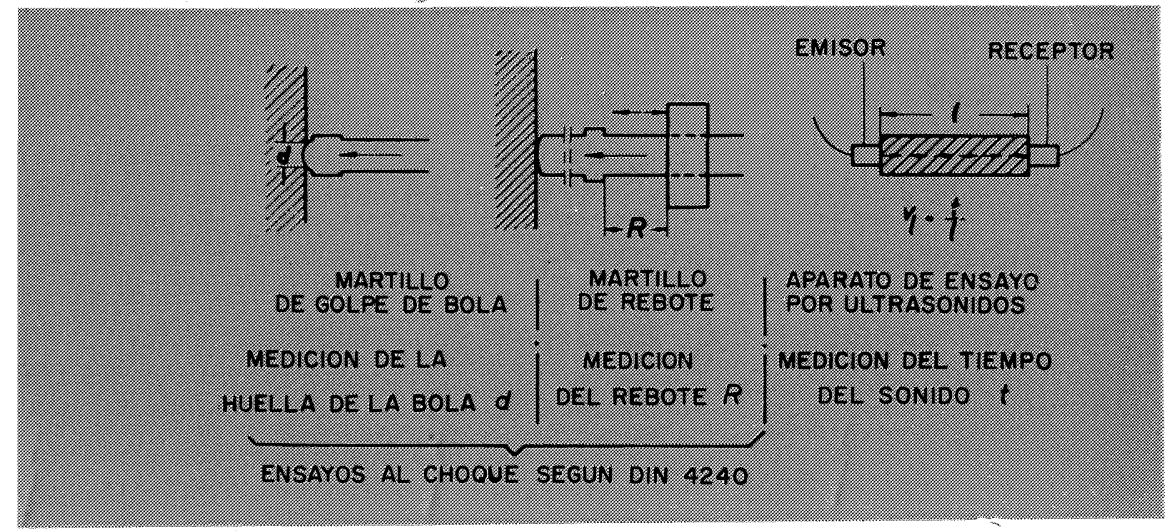

Fig. 1.-Forma de actuar los procedimientos de ensayo no destructivos.

\section{Errores en el ensayo del golpe de bola}

Puesto que el hormigón sufre rotura en caso de someterlo a la compresión por sobrepasar la resistencia al empuje y al cizallamiento, que dependen estrechamente de la deformación plástica, y puesto que, por otra parte, la deformación elástica depende de más variables que la resistencia a la compresión, debiera ser más exacto el método de medida de la huella que los otros dos. Cuando, a pesar de ello, se presenta una gran dispersión, el motivo principal reside en que no se golpea nunca sobre cemento puro y el árido dificulta la deformación más o menos según el tamaño del grano. En el caso de áridos gruesos -en los que es más fácil tropezar con un grano grueso- y en el caso de gran contenido de dichos áridos, resulta un diámetro menor que induce a error al considerar al cemento con una mayor resistencia. Además, la influencia del árido se hace menor al crecer la resistencia del hormigón, porque son menores las huellas y, con ello, también la posibilidad de golpear sobre un grano grueso o en la proximidad del mismo.

La influencia del elevado contenido de cemento y, en consecuencia, de la elevada proporción de pasta de cemento endurecida, se muestra en la figura 2, según los ensayos de Gaede (3).

Puesto que la bola de golpeo presenta menos dificultades cuanto mayor volumen de pasta de cemento existe, resultan las huellas demasiado grandes y hacen creer en una baja resistencia a la compresión. Los valores para hormigones con contenido creciente en cemento $>400 \mathrm{~kg} / \mathrm{m}^{3}$ caen por lo tanto, en gran parte, fuera de la zona de dispersión 
de la norma dada para la valoración de los resultados de medida. En la figura 3 se representan las desviaciones en función del contenido de cemento: según esto, los valores de la norma sólo se podrían utilizar para contenidos de cemento comprendidos entre 250 y $300 \mathrm{~kg} / \mathrm{m}^{3}$. Contenidos de cemento más pequeños dan valores demasiado grandes; y para contenidos mayores, las resistencias a la compresión son demasiado pequeñas.

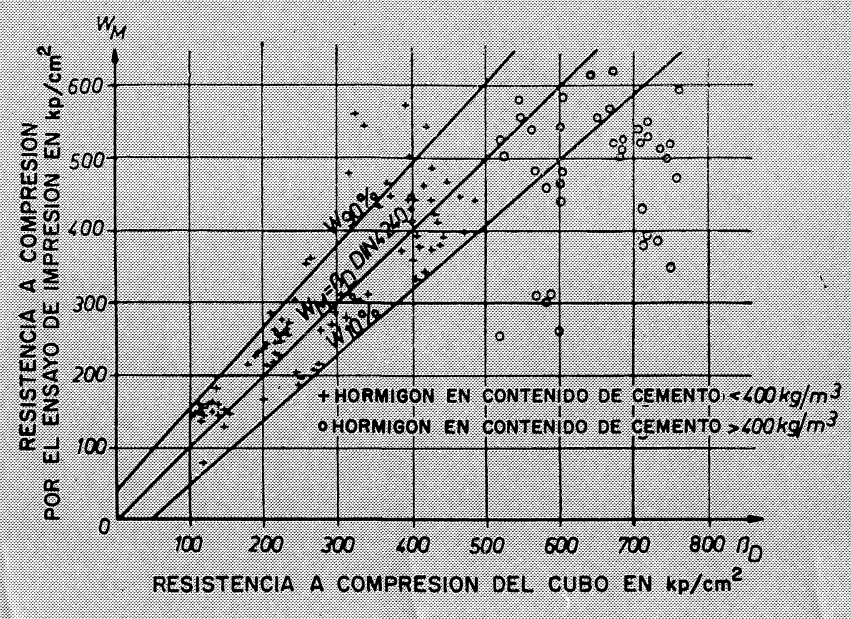

Fig. 2.-Influencia del contenido de cemento sobre los resultados del ensayo por impresión.

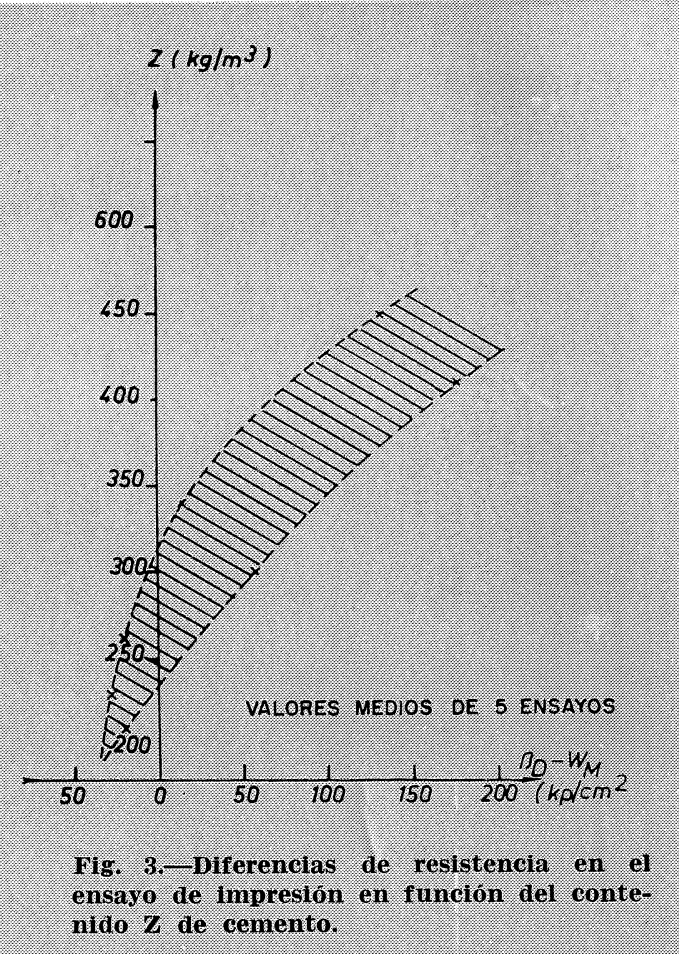

\section{El módulo $E$ y la resistencia a la compresión se influencian de diferente modo}

El módulo de elasticidad y la resistencia a la compresión se influencian, en primer lugar, por la resistencia de la pasta endurecida, es decir, por la resistencia normal del cemento, la relación agua/cemento, el grado de endurecimiento y la cantidad de agua ligada químicamente. Además, existen una serie de factores que actúan solamente sobre el módulo $E$ y que hacen muy indeterminada la función entre el módulo $E$ y la resistencia a la compresión. Dicha función simplificada puede ser expresada según L'Hermite:

$$
\text { Módulo } E=k \sqrt{\text { Resistencia a la compresión, }}
$$

o bien:

$$
E=k \cdot \sqrt{\beta_{\mathrm{D}}} \text {. }
$$

En las normas del Comité Europeo del Hormigón (4), en las que está contenida esta fórmula para la determinación del módulo $E$, se da el factor $k$ como una constante del orden de 21.000. En realidad se dispersa el valor en un amplio margen comprendido entre 
7.000 y 30.000 . En la figura 4 se han representado valores de un trabajo de investigación que se realiza actualmente en el Instituto para la Investigación en Construcción de la Escuela Técnica Superior de Aachen. De dicha investigación no solamente se deduce que el factor $k$ tiene una gran dispersión, sino que se hace más pequeño a mayor edad. Una reducción del valor $k$ significa que, en el endurecimiento del hormigón, el módulo $E$ aumenta menos que la resistencia.

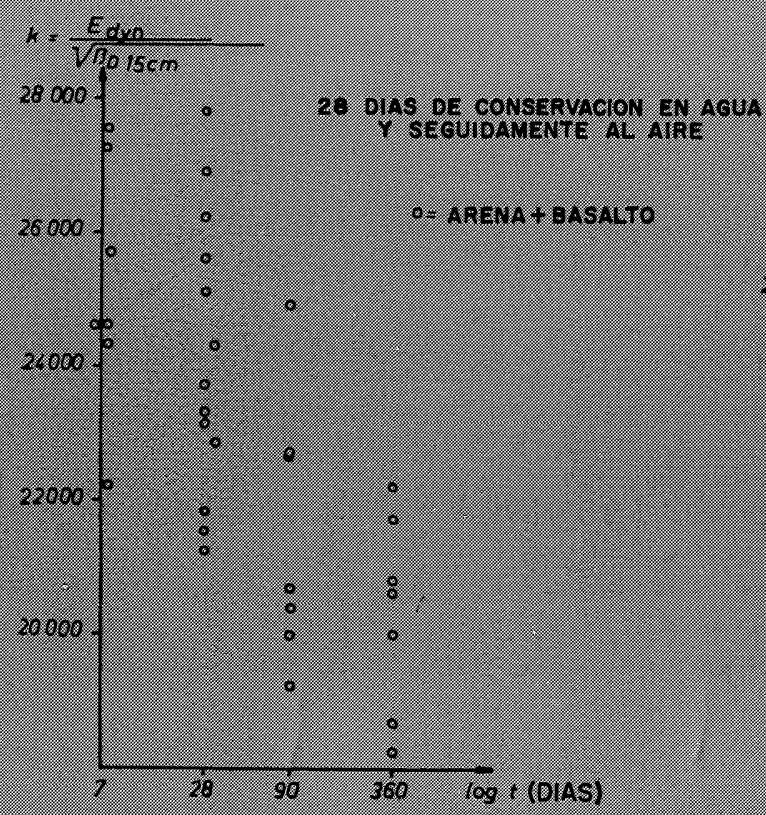

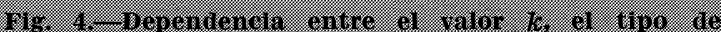
conservacion is la edan (valores indivinales).

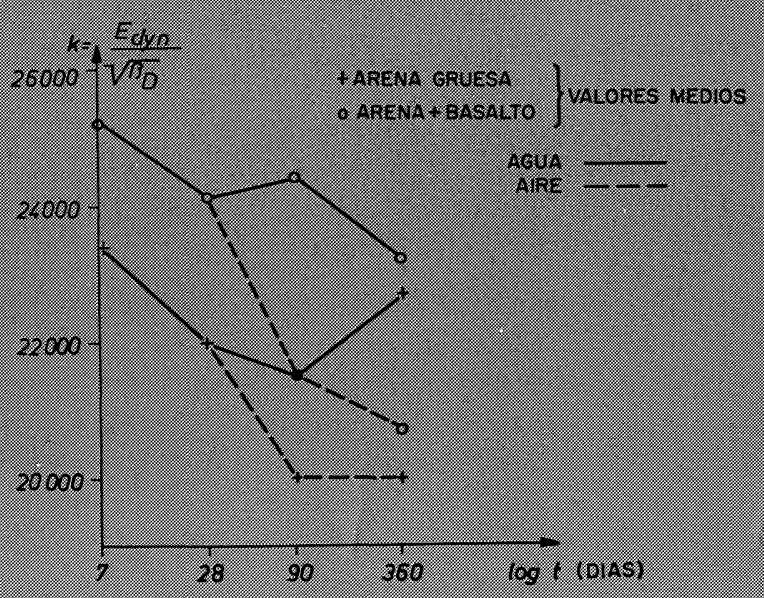

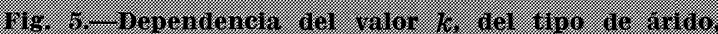

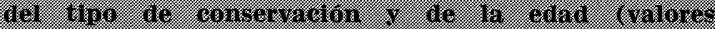
nealios).
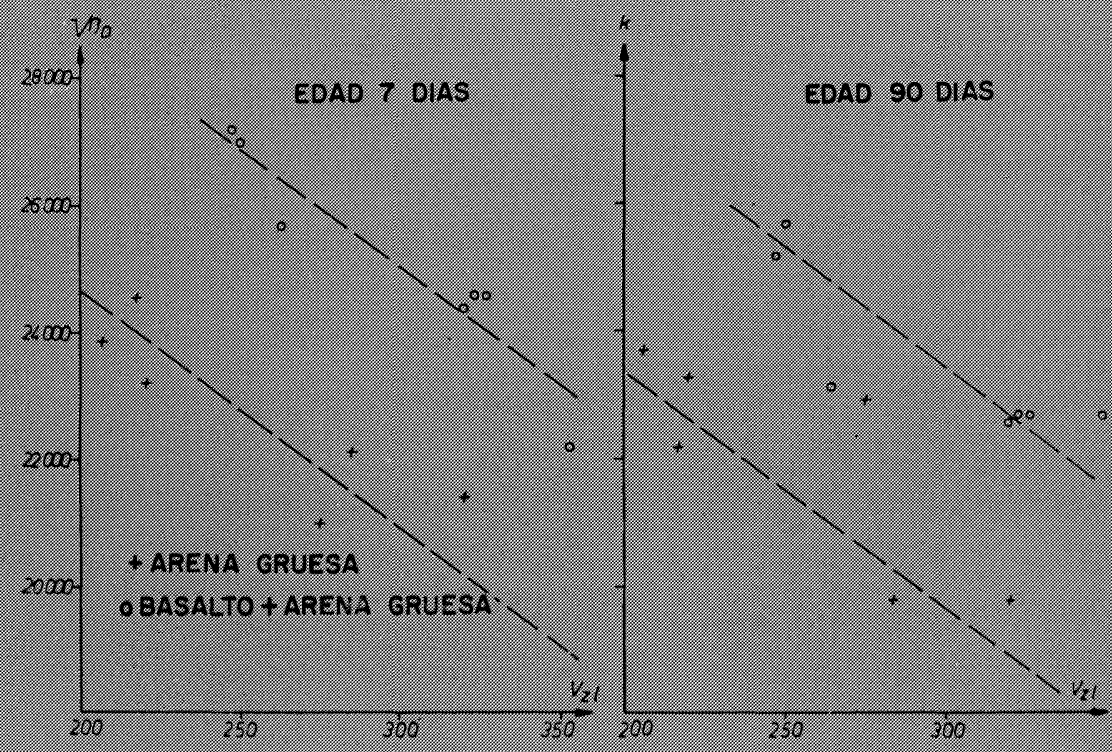

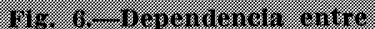

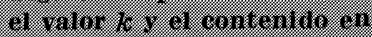

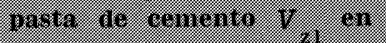

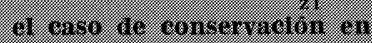
asia. 
Las influencias son más fácilmente visibles cuando son considerados los valores medios en la figura 5 como valores particulares: es fácil reconocer la influencia de la edad, de la conservación y de los áridos.

Con el basalto como árido, el valor $k$ llega a ser hasta 3.000 , mayor que con arena gruesa; como consecuencia de la influencia de la conservación, se puede presentar la misma diferencia. Con mayor volumen de pasta de cemento y, por lo tanto, menor contenido de áridos, $k$ es menor, o sea, que para la misma resistencia a la compresión desciende el módulo $E$ del hormigón, ya que la pasta de cemento es normalmente el componente viscoso y más fácil de conformar (fig. 6). También aquí se puede interpretar fácilmente la influencia del tipo de árido. En el caso del hormigón ligero con áridos que tienen un bajo módulo $E$, pueden ser inversas las relaciones.

Por cálculo se obtienen, según Weigler y Kern (5), las funciones de la figura 7, que destacan la influencia de la velocidad del sonido como consecuencia del módulo $E$ de la pasta de cemento, que depende, principalmente, de la relación agua/cemento del módulo $E$ del árido y del contenido de árido. Finalmente, la composición granulométrica del árido juega un papel importante: con áridos finos, la superficie recubierta por la pasta de cemento es mayor que con áridos gruesos, con lo que resulta: menor el espesor de la película de dicha pasta, es decir, la distancia entre los granos de árido; la fase deformable más fina, y el módulo $E$ y el valor $k$ mayores. En la figura 8 se puede ver la magnitud de esta influencia: entre las líneas de trazos $D$ y $F$ hay una diferencia de 4.000 en el valor $k$, o sea, que el módulo $E$ del hormigón con árido más fino es, para la misma resistencia a la compresión, un $20 \%$ mayor que el del hormigón con árido.

De todo lo dicho se deduce que, en general, no se puede calcular con seguridad la resistencia a la compresión mediante el módulo $E$, ya que se ha de contar con un gran margen de dispersión. Sólo se puede prever una exactitud suficiente, cuando se mantienen constantes las influencias adicionales, tales como tipo, volumen y composición granulométrica de los granos del árido, y se ensaya con la misma conservación y edad. En la mayor parte de los casos de daños y conflictos no se pueden conocer o tomar en consideración las influencias climáticas y, entonces, sólo será posible estimar, con poca aproximación, la resistencia a la compresión.

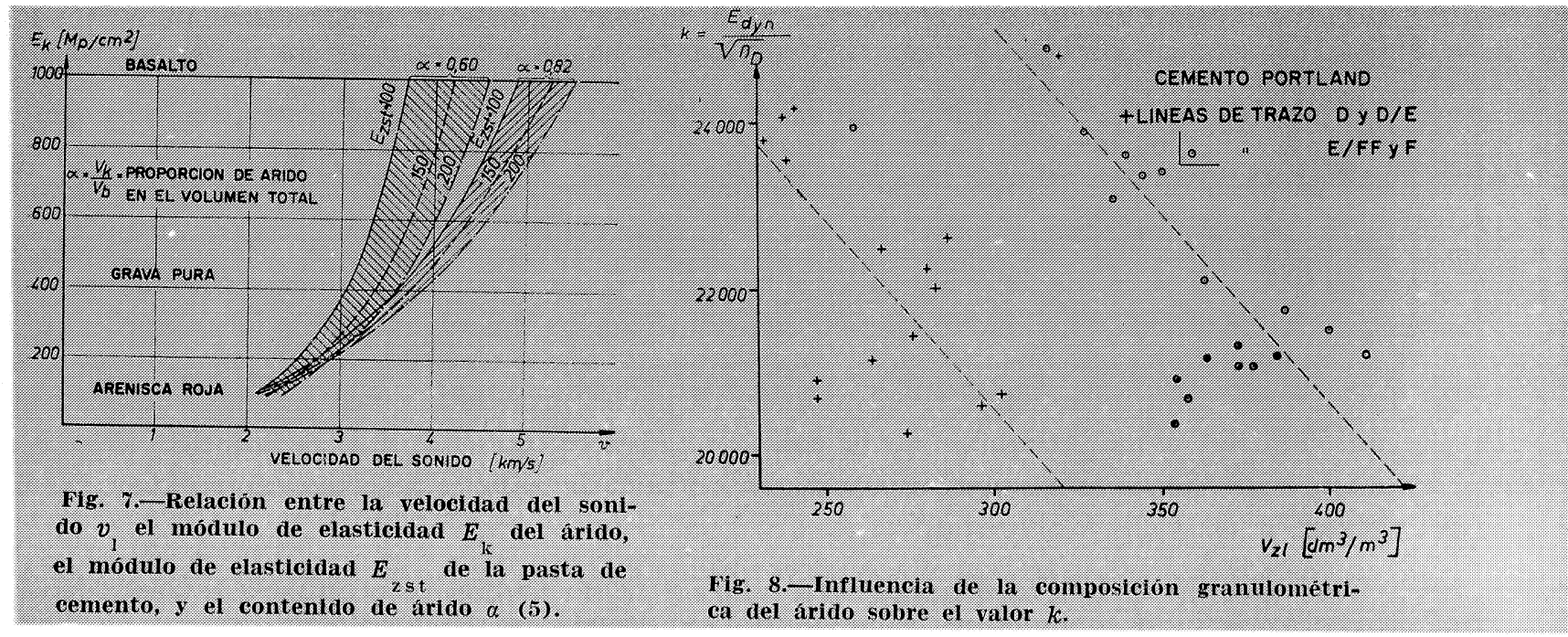




\section{Influencia de la dureza superficial}

Además de las variadas propiedades que son ensayadas con los tres procedimientos, hay que añadir que el hormigón se estudia en diferentes zonas: los procedimientos de golpe se limitan a las zonas externas; por el contrario, el ensayo por ultrasonidos facilita un valor medio de la sección ensayada. Cuando con el procedimiento de golpe sólo se abarca la superficie, juegan un papel importante todas las circunstancias que traen consigo una diferencia entre la resistencia de la superficie y la del núcleo. Estas diferencias son originadas por la diferente hidratación del cemento, grado de secado del mismo y por la transformación química por carbonatación debida a la absorción de $\mathrm{CO}_{2}$ del aire. Las huellas de la esfera son mayores y menores los valores de rebote en el caso de una superficie húmeda que cuando se trata de una superficie seca (6). Si dicha circunstancia exige ya una superficie seca en el hormigón, la carbonatación tiene mayor importancia. La profundidad de la capa carbonatada depende: de la porosidad de la pasta de cemento, de las circunstancias climáticas (principalmente de la humedad del aire) y, posiblemente, del tipo de cemento. Esta capa oscila entre 0 y $40 \mathrm{~mm}$ aproximadamente.

Como consecuencia de las transformaciones químicas, queda modificada la resistencia del hormigón en la zona superficial; por ejemplo, la resistencia se hace mayor por la conversión del hidróxido cálcico $\mathrm{Ca}(\mathrm{OH})_{2}$-que se forma durante la hidratación del clínker del cemento portland- en carbonato cálcico $\mathrm{CO}_{3} \mathrm{Ca}$; por el contrario, se hace menor la resistencia por la conversión de las etringitas (sulfoaluminatos cálcicos hidratados) -que se forman durante el endurecimiento del cemento sobresulfatado- en sulfato cálcico $\mathrm{SO}_{4} \mathrm{Ca}$. En casos extremos se debe contar con diferencias de resistencia entre el núcleo y la superficie del \pm 50 por ciento.

En el Instituto de Investigación en la Construcción de la Escuela Técnica Superior de Aachen nos encontramos, como consecuen cia de una investigación, con la mencionada disminución de la resistencia con el cemento sobresulfatado (7), lo que dio lugar a una pequeña serie de ensayos con distintos cementos y publicados por Manns y Satz (8). En ellos se determinó la modificación de la resistencia de prismas de mortero conservados en aire enriquecido en $\mathrm{CO}_{2}$. En la figura 9 se han representado los valores relativos de resistencia a la compresión, expresados en tanto por ciento de la resistencia a la compresión al comenzar el período de conservación, en función del tiempo. Las resistencias relativas muestran diversas ten dencias según el cemento, pero no se modifican más después de la carbonatación. Los resultados asegurados estadísticamente muestran que las probetas de cemento de horno alto I, cemento de horno alto puzolana II y cemento sobresulfatado pierden en resistencia, en tanto que las de $\mathrm{HOZ}$ II, $\mathrm{Tr}$ HOZ I y cemento portland, ganan.

La suposición de que la modificación de la resistencia a la compresión depende de la cantidad de hidróxido de calcio liberado, que por otra parte se influencia por el contenido en clínker del cemento, nos acerca a la conclusión de que existe una relación entre el contenido en clínker del cemento y las variaciones de resistencia a la compresión. En la figura 10 se representa la relación entre la resistencia relativa a la compresión y el contenido en clínker después de la completa carbonatación: una vez referida a la resistencia de 28 días (valores superiores), y otra, a la resistencia al comienzo de la conservación en $\mathrm{CO}_{2}$ (valores inferiores).

La regresión de estos valores experimentales pueden expresarse mediante líneas rectas. Es decir, se va a suponer un principio (una confirmación hecha por sucesivos trabajos de investigación) que la carbonación influye la resistencia de la superficie del hormigón 
de diferente modo, según el tipo de cemento, siendo mayor que la resistencia propia del hormigón con un contenido en clínker por encima del $40 \%$ y menor por debajo de dicho porcentaje. Tales diferencias de resistencia son consideradas en la norma alemana sólo, de un modo general, mediante un factor de tiempo $\alpha_{t}$, que es $<1$ para una edad superior a los 30 días. Es decir, en todo caso se cuenta con un aumento de la resistencia de la superficie frente a la del núcleo.

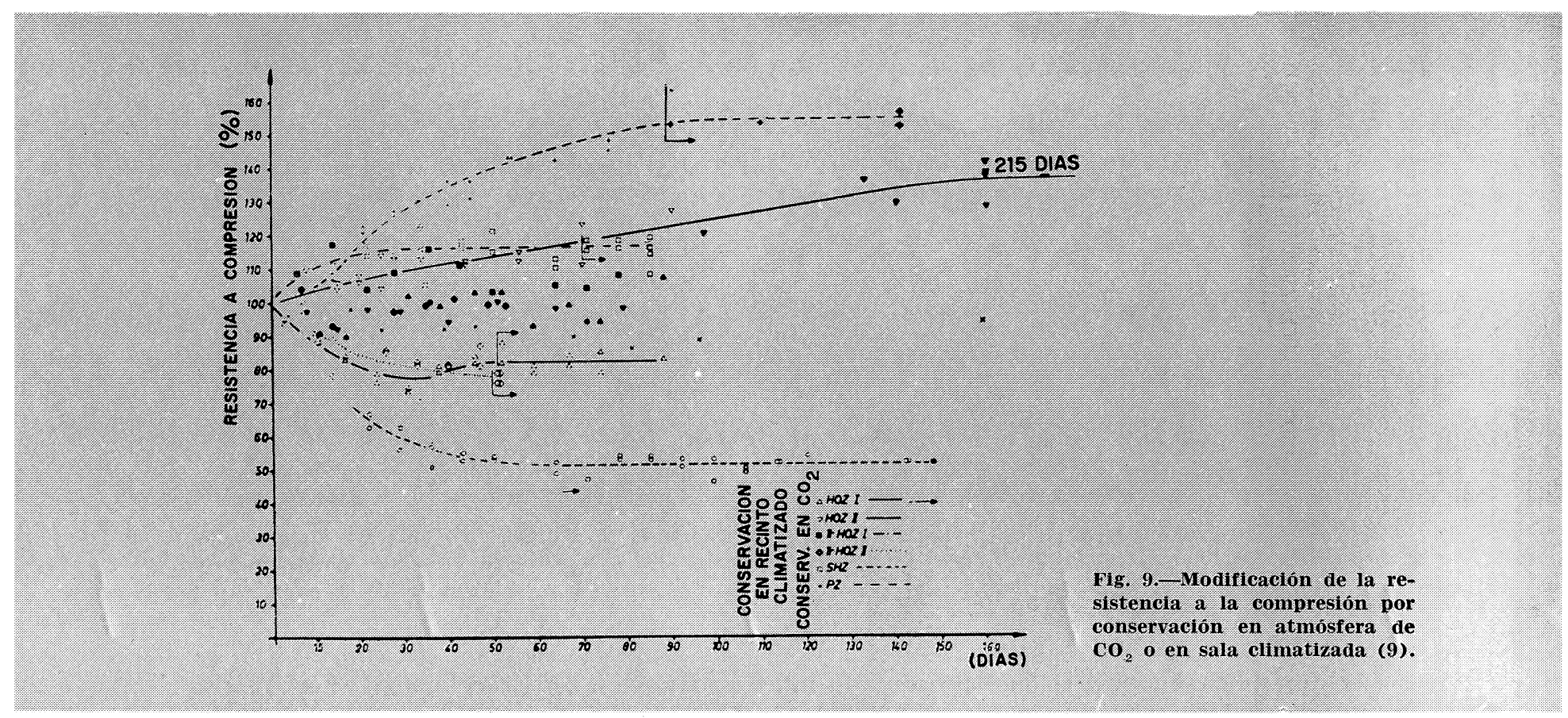

En el caso del cemento portland, la resistencia a la compresión por conservación en $\mathrm{CO}_{2}$ es de 1,6 a 1,7 veces más elevada que con endurecimiento normal, lo que corresponde muy bien, como valor recíproco, al factor de tiempo $\alpha_{\mathrm{t}}=0,60$, según DIN 4240 , para elevada edad del hormigón. Esto se debe a que el factor de tiempo se determinó con experiencias en las que sólo fue utilizado cemento portland. O lo que es lo mismo, estos factores de tiempo sólo deben utilizarse en el caso de hormigones con cemento portland. Por otra parte, el aumento de la resistencia sobre la superficie con cemento portland es siempre el mayor, de modo que, empleando los factores de tiempo de la norma, se está siempre del lado de la seguridad. Una excepción la constituye el cemento aluminoso, del que se hablará más adelante.

En hormigones de cementos especiales se podría demostrar la influencia del tipo de cemento sobre la valoración del ensayo al golpe. En el marco de la investigación de hormigones con cemento sobresulfatado fueron ensayados 54 cubos de hormigón con edades comprendidas entre 5 y 10 años y que fueron almacenados al aire libre hasta el ensayo (9). Según la norma se debía haber contado con un factor de tiempo $\alpha_{t}$ de, aproximadamente 0,60 . Pero las resistencias a la compresión (fig. 11) hubieran resultado aún demasiado reducidas con el ensayo de impresión, incluso sin considerar un factor de tiempo. Los errores sistemáticos frente a los valores de la norma implican aproximadamente el factor 0,70 . 
Por este valor $(0,7)$ debieron dividirse los valores de norma para hormigones viejos de cemento sobresulfatado, en lugar de utilizar el factor corriente, es decir, que el factor $\alpha_{\mathrm{t}}$ debiera ser:

$$
\frac{1}{0,7}=1,4 \text {, en lugar de } 0,60
$$

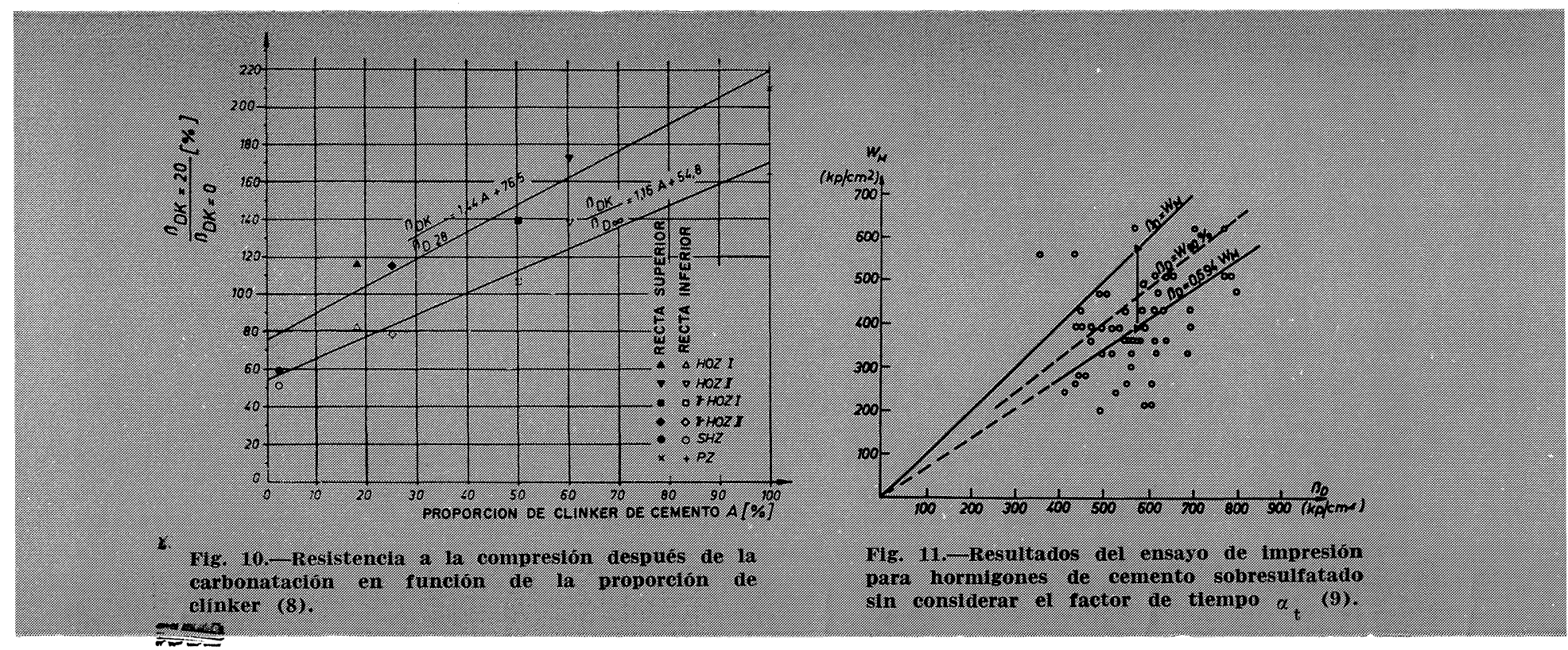

\section{身里}

En la República Federal se han presentado muchos daños en construcciones de hormigón armado y pretensado con cementos aluminosos. Como es conocido, existe una transformación de los productos de hidratación de este cemento, sobre todo en clima cálido y húmedo, que conduce a una reducción de la resistencia y a la corrosión de las armaduras de acero. Por este motivo se deben renovar muchos centenares de miles de $\mathrm{m}^{2}$ de techos en la industria, escuelas, establos y, quizás, en viviendas, a causa de no tener ya la resistencia necesaria.

Debido a que la transformación y, con ello, la pérdida de resistencia, es una función del tiempo y del clima, sería ventajoso que se pudiera determinar, con el ensayo de la hueila, el momento en que la resistencia resulta insuficiente. Las experiencias efectuadas en el instituto en 17 losas de techo y tres cilindros de hormigón de cemento aluminoso, mostraron (fig. 12) que para este cemento tampoco es válida la norma. Sólo cuando el hormigón no se ha transformado o lo ha hecho débilmente, los valores se sitúan dentro de la dispersión de la norma. En el caso de transformacin completada o en avanzado estado, las resistencias a la compresión calculadas resultan el doble de su verdadero valor, es decir, que $\alpha_{\mathrm{t}}$ debiera ser 0,30 en lugar de 0,60.

Cuando en ambos procedimientos de impresión se examina la resistencia de la superficie, existe, sin embargo, una diferencia significativa entre ellos: en el ensayo de la huella se determina la deformación plástica en una profundidad de pocos $\mathrm{mm}$; por el contrario, en el ensayo de rebote se afecta el hormigón en una profundidad de varios centímetros (2). Con diversas profundidades de carbonatación se deben obtener, por lo tanto, distintos resultados con ambos métodos. 
Además hay que recordar las determinaciones de Garde y Schmidt (10) representadas en la figura 13, según las cuales los factores de tiempo para edades por encima de 28 días son casi siempre mayores en el ensayo al rebote que en el de huella. En parte, el factor de tiempo es independiente de la edad y constante con un valor aproximado igual a 1 ; o, lo que es lo mismo, el espesor de la capa con una elevada resistencia fue tan pequeño que ya no pudo ser determinado con el ensayo al rebote.

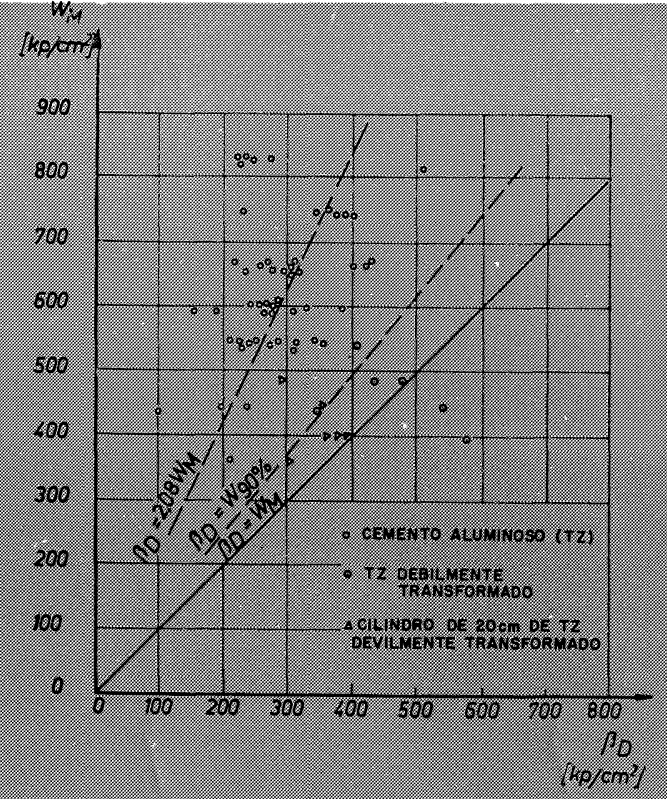

118. 12.- Resuitailos del ensajo a la huella con hormisones de cemento almminoso (9).

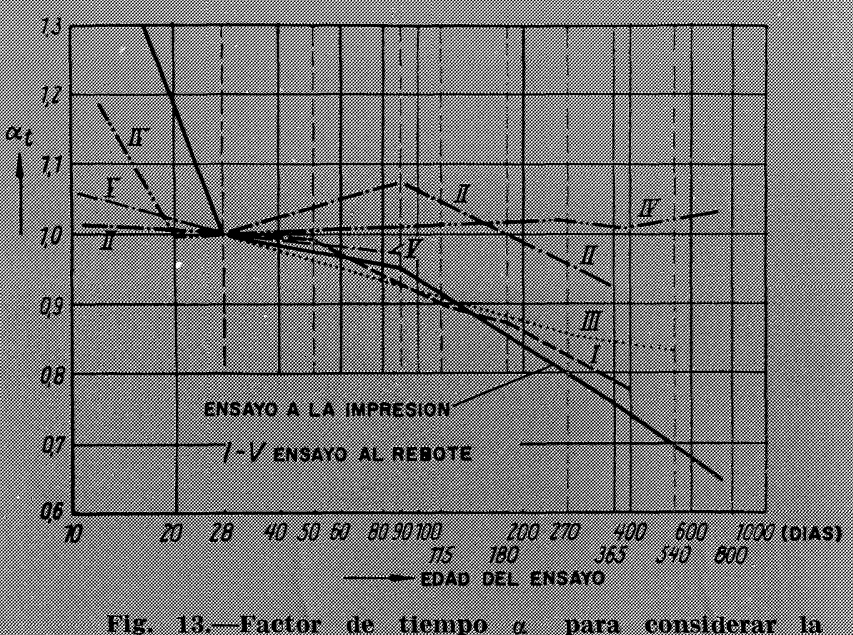

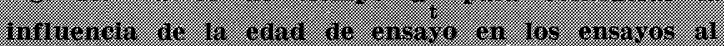
$801100 .(10)$

Con procedimientos de fabricación especiales, en los que, frente del normal endurecimiento, la resistencia de la superficie se influencia de otra forma (por ejemplo con tratamiento de vapor, endurecimiento al vapor en autoclave y tratamiento al vacío), los procedimientos de golpe no pueden ser utilizados sin ensayos adicionales comparativos, por los motivos anteriormente indicados.

\section{Influencias adicionales en construcción}

Los valores de la norma fueron determinados relacionando muchos centenares de experiencias. Los resultados de dichas experiencias, la línea de probabilidad media y el campo de dispersión en el que caen el $80 \%$ de todos los valores, se han representado en la figura 14 (3) y (10). Para relacionar la resistencia a la compresión y el rebote se puede aplicar una recta y para comparar la resistencia a la compresión con la medición de la huella se puede emplear una parábola de $4 .^{\circ}$ grado. Al considerar el campo de dispersión, debe tenerse en cuenta, sin embargo, que en todos los casos se trataba de probetas armadas que fueron almacenadas en el laboratorio bajo condiciones normales.

En la obra no se rècoge nunca la influencia de los diversos encofrados y las variables circunstancias climáticas. Hay que añadir además que durante el vertido y compactación del hormigón en la obra, tiene lugar casi siempre una disgregación en sentido ver- 
tical, sobre todo en el caso de hormigones de consistencia blanda. En el ensayo de superficies horizontales inferiores, se determinan en general un valor demasiado favorable, sobre todo si se emplean encofrados de madera absorbente. Esto también fue determinado por Gaede y Schmidt (10) en el ensayo de cubos de hormigón de superficies inferiores y laterales. También existen experiencias belgas (11), que denotaron la influencia de diferentes superficies: con superficies rugosas, los valores medidos fueron demasiado pequeños y para superficies de encofrado lisas fueron demasiado grandes. A consecuencia de las influencias adicionales en la obra, no eliminables, el campo de dispersión debe ser considerablemente mayor que con las probetas en el laboratorio.

Esto se confirmó mediante investigaciones en obra [ver también (11) y (12)]. Desde hace muchos años el Instituto de Investigación en la Construcción de la Escuela Técnica Superior de Aachen, sólo efectúa los ensayos al choque cuando simultáneamente pueden ser tomadas probetas testigo. Las figuras 15 y 16 (13) muestran los valores de lus resultados de estos ensayos. Con la medición del rebote existían 49 valores disponibles. Las resistencias a la compresión determinadas con el martillo de rebote, según DIN 4 240, estuvieron situadas entre 100 y $400 \mathrm{kp} / \mathrm{cm}^{2}$ y, sin embargo, las verdaderas oscilaron entre 30 a $280 \mathrm{kp} / \mathrm{cm}^{2}$. La recta de regresión media que pasa por el origen del eje de coordenadas y por el centro del conjunto de puntos transcurre en gran parte fuera del campo de dispersión dado en la norma (aproximadamente el $60 \%$ sobre $W_{\mathrm{M}}$ ). Según experiencias holandesas y de Daxelhofer (14), parte de las diferencias de resistencia puede ser atribuida a que el hormigón en las obras sólo se examina en carga y, por lo tanto, el rebote es mayor cuanto mayor es la tensión del hormigón. En los ensayos de huella se dispuso de 84 valores.

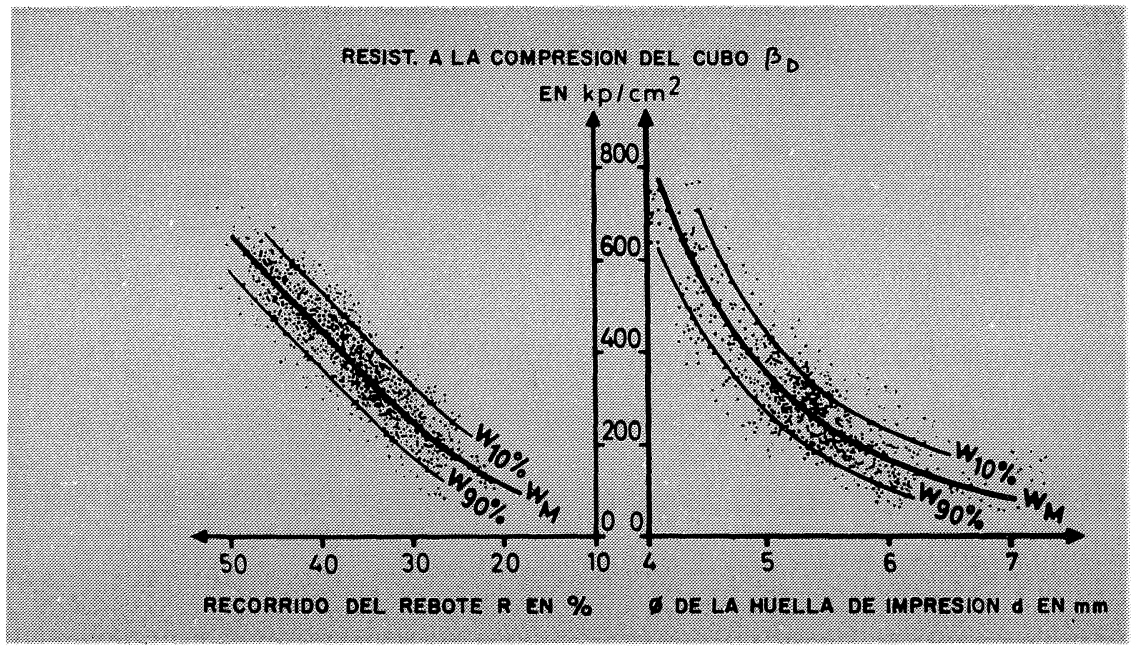

Fig. 14.-Relación entre la resistencia a la compresión y los valores del ensayo al choque (3) y (10).

Las resistencias a la compresión determinadas con el martillo de resorte estaban comprendidas entre 90 y $400 \mathrm{kp} / \mathrm{cm}^{2}$ y las reales entre 40 y $460 \mathrm{kp} / \mathrm{cm}^{2}$. La recta de regresión se desvía sólo un poco de la que señala los valores $W_{\mathrm{M}}$ de la norma. Las investigaciones muestran que el ensayo de impresión para el estudio del hormigón de obra es más exacto que el ensayo de rebote. Pero también muestran que en el ensayo de la huella y aún más en el ensayo al rebote, se obtienen por término medio resistencias a la compresión demasiado altas. 
De lo que se deduce que tiene también poco valor el determinar valores comparativos en cubos de hormigón fabricados en moldes de acero, si el hormigón no está fabricado en la obra en encofrado no absorbente y si no se almacena el cubo en la propia obra y en las mismas condiciones climáticas que el hormigón de la construcción.

\section{Crítica a la aplicación del procedimiento al choque}

A continuación se reúnen los factores de influencia que tienen un papel en el procedimiento de choque:

Influencias sobre el procedimiento de choque
Impresión
Resistencia de la pasta de cemento
Composición granulométrica del árido
Tamaño máximo del árido
Contenido de pasta de cemento

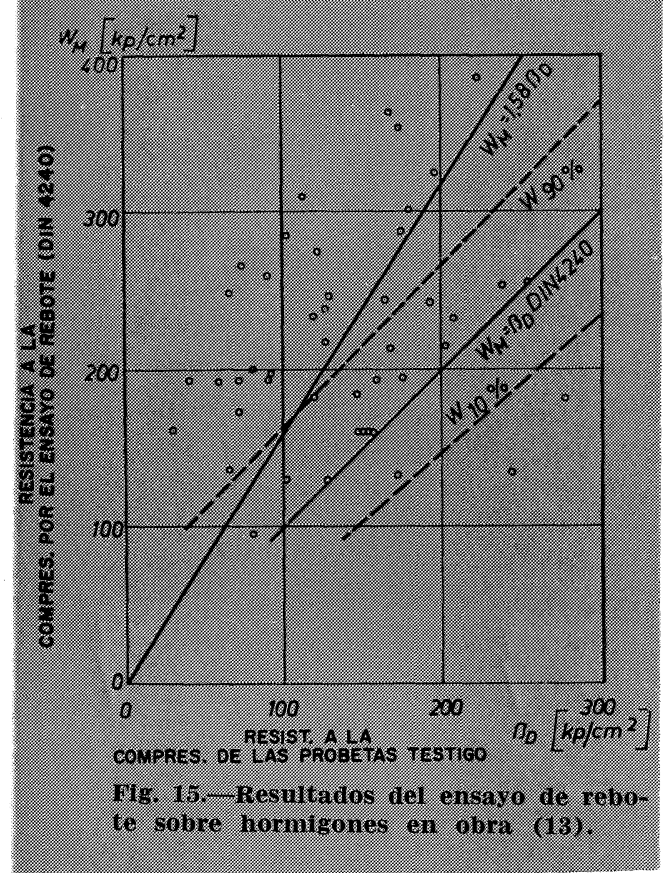

Los factores de influencia impresos en letra negrita no se abarcarán en su conjunto o no se consideran. En un retoque de DIN 4 240, lo que en opinión del autor es necesario con cierta urgencia, se debieran tomar en consideración algunas influencias principales sin ir tan lejos, sin embargo, como las normas rumanas, que parten de un hormigón standard y calculan entonces la resistencia real con 7 factores que son los siguientes (15):

$$
\beta=\beta_{\mathrm{s}} \cdot C_{\mathrm{d}} \cdot C_{\mathrm{z}} \cdot C_{\mathrm{k}} \cdot C_{\mathrm{D}} \cdot C_{\mathrm{g}} \cdot C_{f} \cdot C_{t},
$$

en la cual:

$\beta_{\mathrm{s}}=$ Resistencia a la compresión para el hormigón standard.

$C_{\mathrm{d}}=$ Influencia de la composición del hormigón.

$C_{\mathrm{z}}=$ Influencia del tipo de cemento.

$C_{\mathrm{k}}=$ Influencia del tipo de árido.

$C_{\mathrm{D}}=$ Influencia del tamaño máximo de grano.

$C_{\mathrm{g}}=$ Influencia de la composición granulométrica.

$C_{\mathrm{f}}=$ Influencia de la humedad.

$C_{\mathrm{t}}=$ Influencia de la temperatura de endurecimiento. 
Los procedimientos de golpe, sobre todo el ensayo al rebote, tienen la ventaja de que pueden ser utilizados con aparatos simples por cualquier persona, mientras que el ensayo sónico exige aparatos caros, varias personas para su manejo y conocimientos especiales. La ventaja de la simplicidad del procedimiento es al mismo tiempo una desventaja. Los aparatos de ensayo simples son utilizados por numerosas personas que no poseen los conocimientos tecnológicos del hormigón necesarios y, por lo dicho hasta ahora, son necesarios para poder utilizar los aparatos con sentido y poder enjuiciar correctamente los resultados.

Se puede criticar una creciente mala utilización por parte de las oficinas de arquitectos, ingenieros, empresas y autoridades; incluso los departamentos oficiales utilizan sin cuidado los procedimientos al choque y sobre todo el de rebote. En casos de pleito se establecen exactitudes hasta de $1 \mathrm{kp} / \mathrm{cm}^{2}$ con el martillo de rebote, y en las actas de juicio se encuentran a menudo certificados y documentos que no contienen ninguna indicación sobre los aparatos de ensayo, valores medidos y criterio seguido en la valoración; tan sólo se señalan las resistencias a la compresión obtenidas con estos procedimientos y, por lo tanto, carecen de valor.

En muchos casos se cree, que sería posible determinar exactamente la resistencia a la compresión cuando se siguen las instrucciones de uso de la norma. La existencia de una norma, que hace poca o ninguna alusión a los límites de su utilización, conduce a una gran tolerancia en el uso de aparatos de ensayo al golpe, lo que origina a menudo peligrosos enjuiciamientos sobre la calidad del hormigón. Además ya se han dado en la norma, para cada valor de medida, dos resistencias a la compresión que caracterizan el gran margen de dispersión: una resistencia $\left(W_{\mathrm{M}}\right)$ que es alcanzada con probabilidad media y una resistencia $\left(W_{90} \%\right)$ que es alcanzada con el $90 \%$ de probabilidad. Para $W_{90} \%$ está situada la dispersión absoluta entre $\pm 20 \%$ en grandes resistencias y entre $\pm 50 \%$ para bajas resistencias.

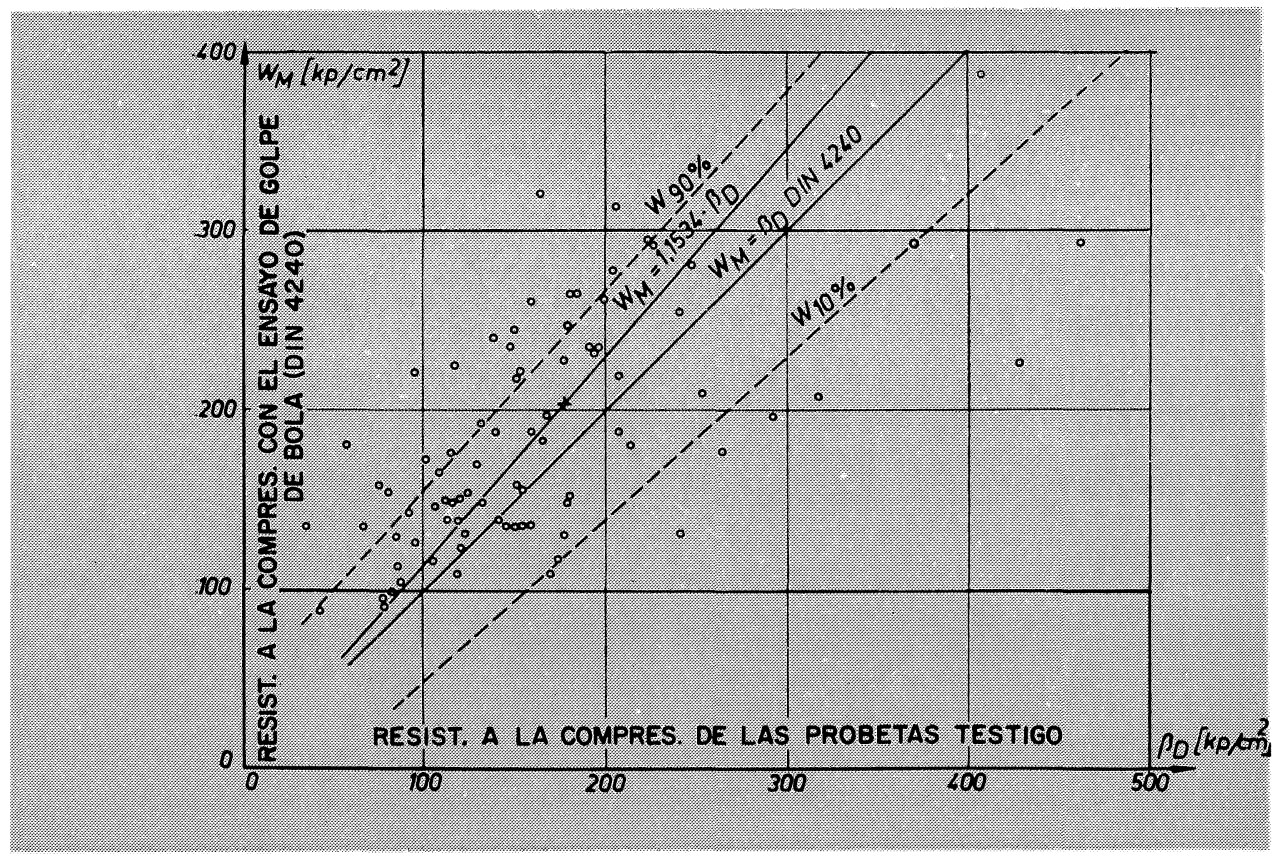

Fig. 16.-Resultados del ensayo de impresión en obras de hormigón (13).

Nosotros ya hemos observado que con frecuencia no es suficiente, para el ensayo en obra, el $90 \%$ de probabilidad. Se debe recurrir, por lo tanto, actualmente, para enjui- 
ciar la calidad del hormigón, a la fracción $5 \%$ de la probabilidad $95 \%$. Con el fin de poder establecer la resistencia de un hormigón, se debe permanecer en el lado de la seguridad y decir, solamente, que la resistencia máxima es con seguridad $W_{90} \%$. La situación exacta de la verdadera resistencia dentro del margen de dispersión no puede indicarse en ningún caso.

Por consiguiente la norma DIN 4240 debe modificarse respecto al $5 \%$, restringiéndola respecto a las influencias individuales. El campo de aplicación debe delimitarse lo más exactamente posible $(*)$.

\section{Influencias adicionales en el ensayo sónico}

Partiendo de la velocidad del sonido medida, puede determinarse el módulo $E$ con ayuda de la fórmula:

$$
E=v_{\perp}^{2} \cdot \rho \frac{(1+\mu) \cdot(1-2 \mu)}{(1-\mu)},
$$

en donde:

$$
\begin{aligned}
v_{1}= & \text { Velocidad del sonido. } \\
\rho= & \frac{\text { Densidad del hormigón }}{\text { Aceleración de la gravedad }} \quad \text { (en los áridos rodados } \simeq 2,65 \times 10^{4} \text { ). } \\
\mu= & \text { Coeficiente de Poisson (dilatación transversal). (Con áridos rodados de } \\
& 0,20 \text { hasta } 0,25) .
\end{aligned}
$$

En esta fórmula, $\rho$ y $\mu$ son dos variables que sólo pueden establecerse con suficiente exactitud en los hormigones normales. Cuando el árido o su influencia sobre $\rho$ y $\mu$ no es conocida, se puede presentar en su valoración un error que puede alcanzar el $10 \%$. Esto se debe a que la dilatación transversal del hormigón depende mucho del comportamiento elástico del árido. Además está la gran dispersión que resulta de calcular la resistencia a la compresión partiendo del módulo $E$.

Cuando, como ocurre en el mayor número de casos, se determina la resistencia directamente de la velocidad del sonido, sin parar a través del módulo $E$, puede aumentarse considerablemente el campo de dispersión, como consecuencia de estos factores indeterminados. Además, la fórmula antes indicada sólo es válida teóricamente para cuerpos infinitamente grandes. Es decir, que también influye la forma y el tamaño del elemento constructivo, no habiéndose aclarado hasta la fecha su importancia.

Weigler y Kern (5) ensayaron 60 cubos de hormigón de composición desconocida con distintos áridos (fig. 17).

(*) En la revisión de la norma DIN 1045 se ha previsto la exigencia de que, junto al ensayo no destructivo, se ensayen por rotura probetas testigo extraídas de la obra. Aun asi, debe señalarse que la elaboración de los resultados exige una experiencia especial. También se exige que los valores $W_{95} \%$ sin ensayo destructivo correspondan a la calidad establecida. 
Los resultados muestran que la resistencia a la compresión no puede determinarse sin inconvenientes mediante la velocidad del sonido. Para una determinada velocidad de sonido, la resistencia a la compresión se encuentra entre 200 y $600 \mathrm{kp} / \mathrm{cm}^{2}$. La exactitud puede ser mayor, para cualquier tipo de golpeo, sólo cuando el hormigón se ha preparado con los mismos cementos y áridos. En las medidas de la figura 18 se varió solamente la relación agua/cemento y la cantidad de árido: entonces, el campo de dispersión se disminuye aproximadamente un cuarto. En Delft (16) fueron construidas 30 columnas de hormigón sin armar y de ellas se cortaron 360 cubos que se ensayaron con ultrasonidos sin destrucción y, finalmente, se ensayaron con destrucción de los mismos. El cemento y el árido eran los mismos. La composición granulométrica, el contenido de cemento y la relación agua/cemento oscilaron poco.

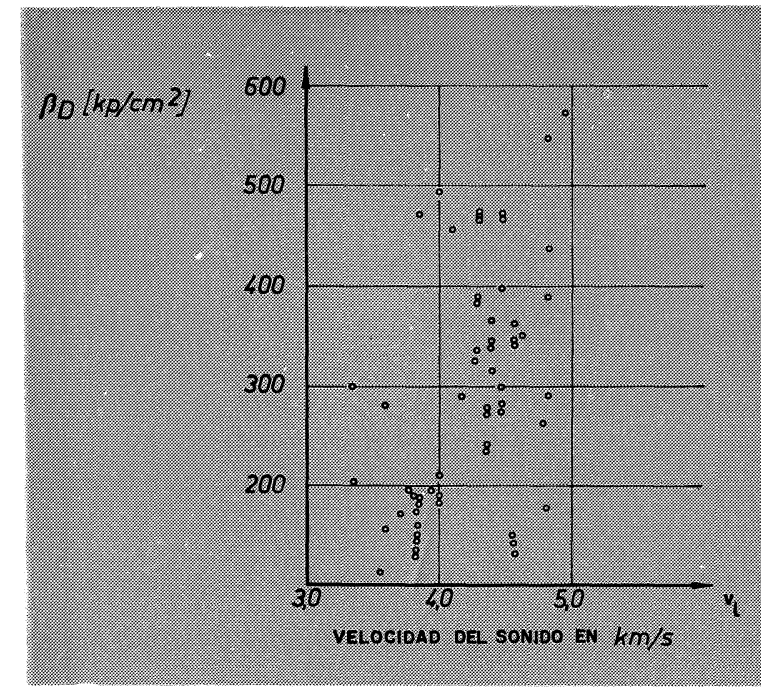

Fig. 17.-Resistencia a la compresión $\beta_{D}$ y velocidad del sonido $v_{1}$ de hormigones con distintos tipos de áridos (5).

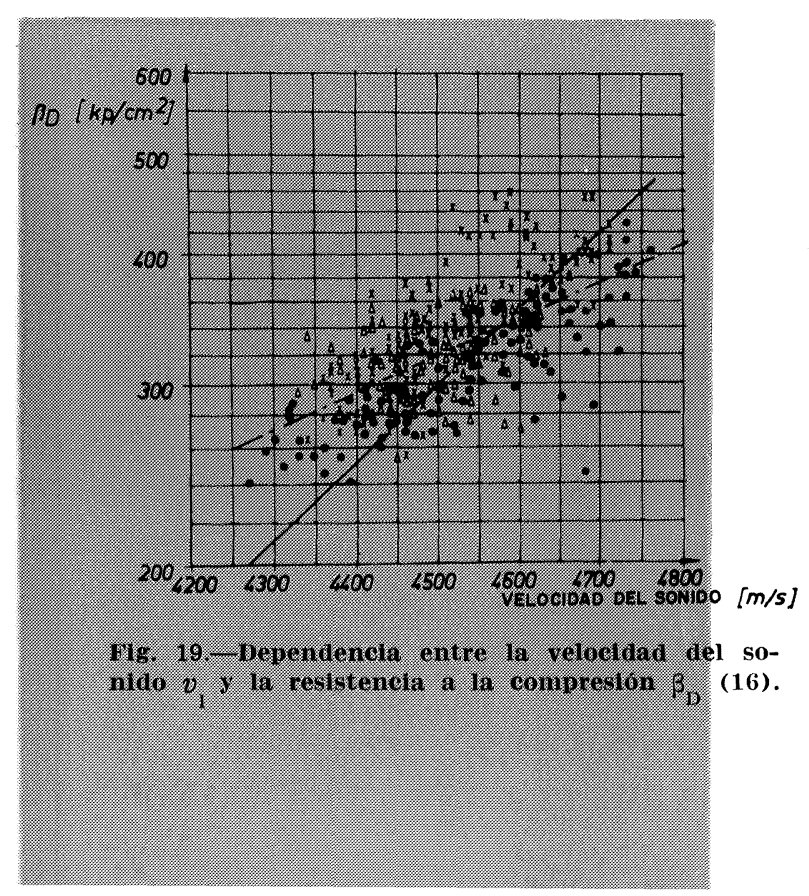

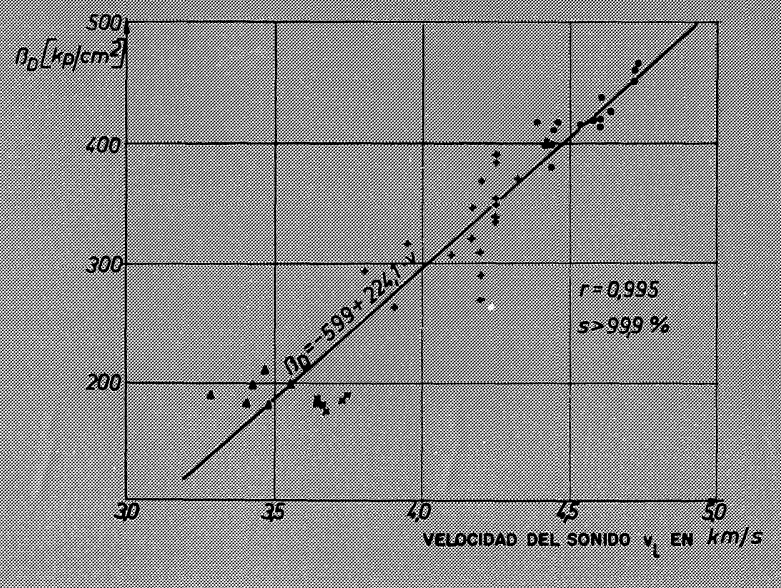

Fig. 18.-Resistencia a la compresión $\beta_{D}$ y velocidad del sonido $v_{1}$ del hormigón hecho con el mismo tipo de árido (5).

A pesar de ello se presentaron grandes diferencias en la resistencia a la compresión, sobre todo grandes dispersiones en la función entre velocidad del sonido y resistencia a la compresión (fig. 19). En las experiencias belgas (11) se estableció, precisamente en el campo inferior de la resistencia, una correlación relativamente buena; el campo de confianza en obra resultó de $\pm 80 \mathrm{kp} / \mathrm{cm}^{2}$ y con todas las experiencias de laboratorio llegó a ser incluso de $\pm 130 \mathrm{kp} / \mathrm{cm}^{2}$, que es una dispersión demasiado grande, sobre todo con las bajas resistencias. 
Además hay aún que añadir la gran influencia del contenido en humedad sobre la velocidad del sonido, ya que, como es conocido, la velocidad es mayor en el agua que en el aire. Según la figura 20 se obtiene con la misma resistencia, pero por conservación en agua, una velocidad del sonido en $0,5 \mathrm{~km} / \mathrm{s}$ mayor, lo que falsea por defecto la resistencia a la compresión en aproximadamente $100 \mathrm{kp} / \mathrm{cm}^{2}$ (5). Estas determinaciones st confirman mediante experiencias en otros países. Mientras que en los ensayos al choque la influencia de la humedad tiene poca importancia si la superficie está seca, en el ensayo al sonido cobra siempre mucho valor.

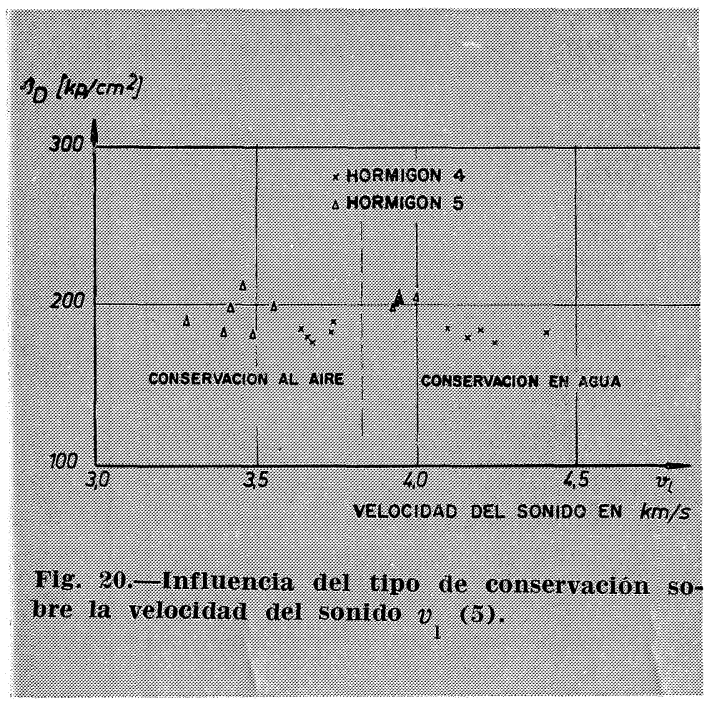

influencia en este sentido. Facaoaru (17) informó en la última sesión del comité RILEM "Ensayos no destructivos del hormigón", celebrado en Aachen, sobre experiencias rumanas, que también permiten reconocer una influencia de la temperatura sobre la velocidad del sonido. Finalmente, se estableció una influencia adicional debida al árido (18); incluso las propias grietas pueden falsear los resultados.

Es decir, que en el ensayo sónico se presentan muchas influencias desconocidas y que no se consideran como en los ensayos al golpe. De ellos no se puede esperar, por lo tanto, ninguna gran exactitud. Esto lo muestra también la norma rumana (18), que marcha de la misma forma en el ensayo sónico que con los de golpe, es decir, que intenta determinar la resistencia real a la compresión mediante un hormigón standard y los correspondientes factores.

Si se multiplican los valores extremos de los factores individuales, puede estar situado el factor total entre 0,23 y 5,3 e, incluso, cuando son solamente desconocidos el tipo de cemento, granulometría y composición del hormigón, los límites son aun 0,4 y 2,0, o sea, que con un hormigón del tipo B 300 sólo se podría decir que la resistencia a la compresión está situada entre 120 y $600 \mathrm{kp} / \mathrm{cm}^{2}$.

Para concluir se han representado en la tabla 1 las ventajas e inconvenientes de los diversos procedimientos de ensayo. 
T A B L A 1

Ventajas e inconvenientes de los procedimientos no destructivos para el ensayo de la resistencia del hormigón en obra

\begin{tabular}{|c|c|c|c|c|}
\hline \multirow[b]{4}{*}{ Ventajas. } & \multicolumn{3}{|c|}{ Ensayos de golpe. } & \multirow{2}{*}{ Ensayo sónico. } \\
\hline & Ensayo de huella & \multicolumn{2}{|c|}{ Ensayo de rebote. } & \\
\hline & \multicolumn{3}{|c|}{ Aparatos simples. } & \multirow[b]{2}{*}{$\begin{array}{l}\text { Medición sobre la sección } \\
\text { completa. }\end{array}$} \\
\hline & $\begin{array}{l}\text { Ninguna influencia del tipo } \\
\text { de árido. Más exacto en obra } \\
\text { que el ensayo de rebote. }\end{array}$ & $\begin{array}{l}\text { Lectura muy c } \\
\text { moda, f ácil } \\
\text { exacta. }\end{array}$ & có- & \\
\hline \multirow{3}{*}{ Desventajas. } & \multicolumn{4}{|c|}{$\begin{array}{l}\text { Gran margen de dispersión, mayor con hormigones de la obra que con los } \\
\text { del laboratorio. } \\
\text { Influencia de la humedad. }\end{array}$} \\
\hline & \multicolumn{2}{|c|}{$\begin{array}{l}\text { Sólo comprende la superficie. Con segregación y } \\
\text { ensayo sobre la cara inferior, valores excesiva- } \\
\text { mente altos. Influencia de la diferente hidrata- } \\
\text { ción, de la carbonatación, de la profundidad de } \\
\text { carbonatación y de la distinta resistencia de la } \\
\text { capa carbonatada. Por eso no se deben emplear } \\
\text { sin ensayos especiales en el caso de cementos es- } \\
\text { peciales, tratamiento de vapor, endurecimiento al } \\
\text { vapor y tratamiento al vacio. }\end{array}$} & \multicolumn{2}{|c|}{$\begin{array}{l}\text { Relación Módulo } E / \text { resistencia a la } \\
\text { compresión, se modifica con el módu- } \\
\text { lo } E \text { y composición granulométrica } \\
\text { del árido contenido en pasta de ce- } \\
\text { mento, edad y tipo de conservación. }\end{array}$} \\
\hline & $\begin{array}{l}\text { Medición trabajosa a menudo, } \\
\text { influencia del tamaño del gra- } \\
\text { no, composición granulométri- } \\
\text { ca y contenido en pasta de ce- } \\
\text { mento. }\end{array}$ & \multicolumn{2}{|c|}{$\begin{array}{l}\text { Rebote mayor con mate- } \\
\text { riales bajo carga. }\end{array}$} & $\begin{array}{l}\text { Aparatos caros, manejo por va- } \\
\text { rios hombres. Influencia adi- } \\
\text { cional de la densidad del hor- } \\
\text { migón y dilatación transver- } \\
\text { sal. }\end{array}$ \\
\hline
\end{tabular}

\section{Conclusiones para el empleo de un procedimiento}

Como consecuencia de las grandes dispersiones en todos los procedimientos de ensayo debe precisarse lo siguiente:

1. Sin ningún conocimiento de la composición del hormigón no puede valorarse con suficiente exactitud la resistencia a la compresión con un método de ensayo. Incluso en obra, no es suficientemente seguro el valor $W_{90} \%$ en el límite inferior del campo de dispersión, según DIN 4240.

2. La calidad puede, sin embargo, establecerse cuando se conoce el tipo de cemento y de árido, así como su influencia sobre los resultados, o sea, cuando existe una curva especial de comparación para esa composición del hormigón y el aparato empleado, y se supone se emplea el mismo encofrado y aproximadamente el mismo endurecimiento. Dichas curvas de comparación no hay que confundirlas con los valores DIN y las curvas que acompañan al aparato. Las últimas no se deben emplear en muchos casos. 
3. Con los procedimientos de ensayo no destructivos se pueden determinar muy bien variaciones de calidad en un elemento u obra, cuando es igual el tipo de cemento y de árido y la composición no varía muy bruscamente. Sobre todo se pueden delimitar con bastante exactitud los campos de buenos y malos hormigones. En este sentido se sitúa propiamente el verdadero significado del procedimiento.

4. La resistencia a la compresión puede determinarse con relativa exactitud, si no se modifica para nada la composición en ?a preparación del hormigón en la fábrica y en los grandes elementos. Las diferencias en la resistencia hay que atribuirlas a las distintas adiciones de agua y a la compactación, disponiendo de suficientes valores de comparación.

\section{Aplicación de varios procedimientos de ensayo}

Cuando el hormigón normal no puede juzgarse con suficiente exactitud por un procedimiento de ensayo, hay que estudiar si se puede elevar la exactitud mediante el empleo de varios métodos. Según Skramtejew y Leszcinskij (19) existen para ello las siguientes posibilidades (fig. 21):

a) Los campos de dispersión de ambas funciones no se interfieren entre sí: Las mediciones se deben repetir antes de ser utilizado otro procedimiento. (1).

b) Ambos valores medios y los campos de dispersión son aproximadamente iguales: No resulta ninguna mejora de esta afirmación. (2).

c) Los dos campos de dispersión se cruzan: La verdadera resistencia está situada con gran probabilidad en el interior del cruce. (3).

d) Un campo de dispersión más pequeño está situado dentro de los otros: La verdadera resistencia está situada con gran probabilidad en el pequeño campo de dispersión. (4).

$\rho_{i}$

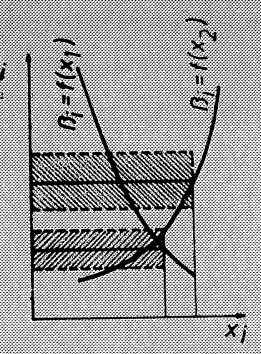

(1)

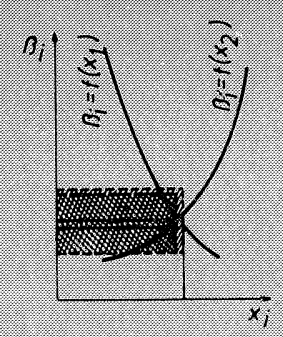

(2)

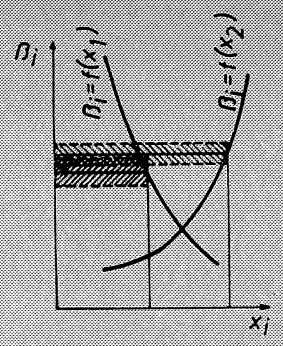

(3)

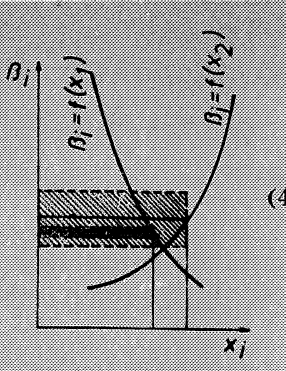

Fig. 21.-Metodos para la determinación del valor de resistencia significativo (19).

Brunarski (20) ha determinado, por cálculo la relación entre la resistencia a la compresión $\beta_{\mathrm{D}}$, el rebote $R$ y la velocidad del sonido $v$, la siguiente función:

$$
\beta_{\mathrm{D}}=0,022 v^{2,682} \cdot R^{1,44}
$$

La función corresponde a las curvas de la figura 22, con cuya utilización se reduce la dispersión en un $30 \%$ en relación con un procedimiento de ensayo.

Facaoaru, Dumitrescu y Constantinescu (17) proponen otro tipo de valoración: ellos establecieron los valores de rebote en función de la velocidad del sonido (fig. 23) y dibujaron entonces líneas de la misma resistencia a la compresión, con las que se pueden 
dar valores más exactos. Este procedimiento se hace muy adecuado para la valoración, cuando se dispone de numerosos valores de los dos procedimientos de ensayo al golpe y las líneas de la misma resistencia son sustentadas por ensayos destructivos.

En lo posible se debe, además, efectuar el ensayo no destructivo, tomar testigos por perforación y ensayar por destrucción. Para relacionar la resistencia a la compresión con destrucción y sin destrucción, varios investigadores han determinado funciones que se han reunido en la tabla 2. Aquí solamente se emplearon fórmulas de validez general y no aquellas que contienen factores especiales para las influencias conocidas y en general desconocidas, como, por ejemplo, las fórmulas de Coune (6) en las que entra el contenido de cemento.

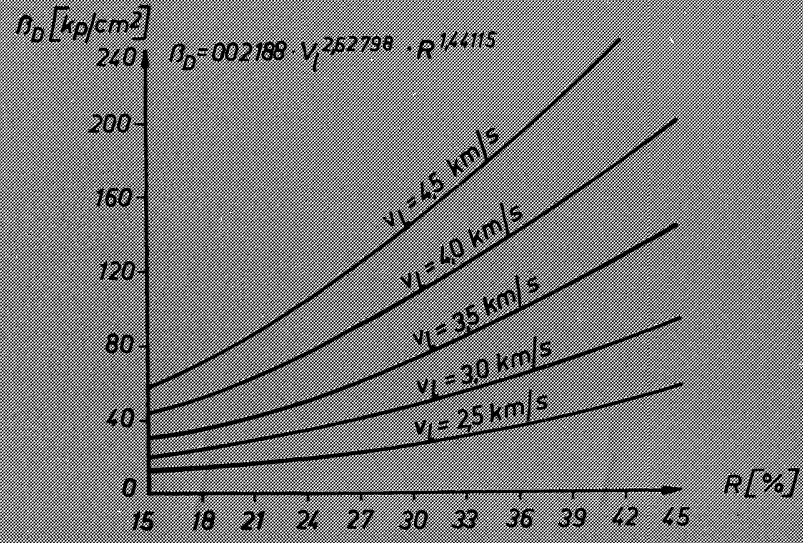

718. 22. Determinacion ae la resistencia a la compreston B, en trinción det rebote hit de la velocidai aler sonilio $v,(20)$.

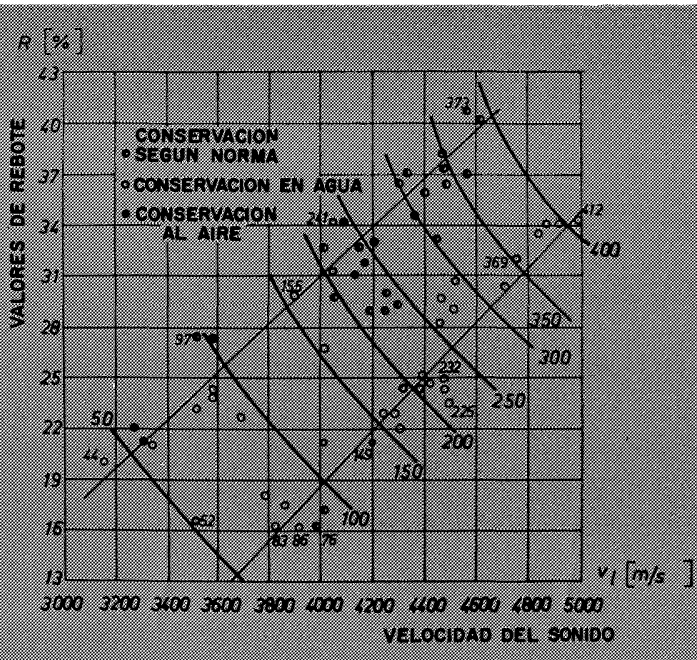

Vig: 23. - Determinacion de la resistericia a la

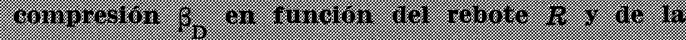
velocidad der sonitio $v,(17)$.

Se puede suponer en general que los valores correspondientes están sițuados aproximadamente sobre una curva dentro del margen de dispersión, que sólo se diferencia en un factor de la función de correlación. Cuando sólo se ensaya sin destrucción y se toma del mismo punto un testigo de perforación, se puede determinar este factor mediante el ensayo destructivo; en el caso de varios testigos de perforación, también puede determinarse su campo de dispersión y ordenar los restantes valores con la función deducida. Con el ensayo al golpe, desaparece la influencia de la edad sobre la dureza de la superficie, o sea, el factor tiempo, y en el ensayo sónico se recoge la influencia del árido y de la humedad.

Así, por ejemplo, se determinan el diámetro, $d$, de la huella en el ensayo de impresión y la resistencia a la compresión, $\beta_{\mathrm{D}}$, de forma destructiva; con ello se calcula el factor $C$ en la ecuación $\beta_{\mathrm{D}}=C \cdot d^{-4}$. Con ayuda de este factor $\mathrm{y}$ dicha ecuación se pueden deducir ahora los restantes resultados de medida sobre la resistencia a la compresión.

Es decir, que con este proceso se necesita solamente la función de correlación, imprescindible, que se puede extraer de la tála 2. Sin embargo, es todavía mejor calcula dicha función para un árido determinado, pero en lo posible no con la ayuda de las probetas de laboratorio sino con los testigos de perforación de la obra. 
T A B L A 2

Relaciones entre los ensayos no destructivos y con destrucción

\begin{tabular}{|c|c|c|c|}
\hline Origen & Ensayo por impresión & Ensayo por rebote & Ensayo por sonido \\
\hline $\begin{array}{l}\text { Brunarski (20). } \\
\text { Campus; Dutron, Coune } \\
\text { (11). } \\
\text { Ciganek, Sedlak (21). } \\
\text { Coune (6). } \\
\text { CUR, TNO Niederlande } \\
\text { (14). } \\
\text { Davance, Jevtic (14). } \\
\text { Facaoaru (15. } \\
\text { Gaede (3). } \\
\text { Gaede, Schmidt (10). } \\
\text { Peltier (14). } \\
\text { Slachta (22). } \\
\text { Weigler, Kern (5). }\end{array}$ & $\begin{array}{l}\beta=282000 d^{-4,16} \\
\text { simplificado } \\
\beta=C \cdot d^{-4}\end{array}$ & $\begin{array}{l}\beta=0,019 R^{2,59} \\
\beta=a R-b \\
(a \approx 17-20, \\
b \approx 180-230) \\
\\
\beta=9,1 R-70 \\
\beta=(0,19 R)^{3} \\
\beta=0,06 R^{2,42} \\
\\
\beta=19 R-330 \\
\beta=18,5(R-20)\end{array}$ & $\begin{aligned} \beta & =0,188 v_{1}^{4,48} \\
\beta & =a+b v_{1} \\
\log \beta & =a+b \log v_{1} \\
\beta & =k v_{1} \\
\log \beta & =a+b \log v_{1} \\
\log \beta & =a+b v_{1} \\
\beta & =a e v_{1} \\
\beta & =\left(v_{1}-b\right)^{\mathrm{n}} \cdot a \\
\beta & =a+b v_{1}\end{aligned}$ \\
\hline
\end{tabular}

Skramtajew y Leszcinskij (19) han desarrollado un procedimiento basado en la estadística para poder valorar también los resultados de los tres procedimientos de ensayo no destructivos; una posibilidad que es más económica que la extracción de testigos, pero que hasta la fecha no se han presentado resultados.

\section{Consideración final}

Se confía haber expuesto con suficiente claridad la difícil problemática del ensayo no destructivo del hormigón. Se consideró necesario, además, describir con claridad las numerosas desventajas que con los conocimientos corrientes deben tomarse en consideración. El empleo del ensayo del hormigón por métodos no destructivos tiene límites, pero dentro de éstos su empleo resulta ventajoso. Fundamentalmente, se pueden extraer las siguientes conclusiones:

1. Un ensayo no destructivo no tiene ningún valor en el caso de un hormigón desconocido.

2. Cuando se ensaya sin destrucción, se deben utilizar por lo menos dos procedimientos de ensayo, de los cuales, a ser posible, uno de ellos debe ser destructivo.

3. No se debiera ensayar la resistencia del hormigón de obra sólo en caso de duda, o sea, cuando es demasiado tarde, sino que debiera incluirse en el proyecto de la obra, es decir, como una vigilancia continua de la misma. Esto es importante, sobre todo en grandes construcciones para el hormigón transportable y para la preparacin de elementos prefabricados.

Si se toman en consideración estas reglas y las limitaciones y posibilidades de evaluación expuestas en este informe, el ensayo no destructivo del hormigón puede ser un valioso medio auxiliar para la determinación de las verdaderas resistencias. 


\section{RESUMEN}

Por diversos motivos es necesario con frecuencia determinar la resistencia del hormigón en la propia estructura. Junto con el ensayo por ultrasonidos se toman en consideración los dos procedimientos de golpeo normalizados según DIN 4240 . El uso especial de estos procedimientos simples de ensayo obliga a conocimientos tecnológicos profundos del hormigón. Además las bases de ambos procedimientos al golpe son diferentes y, con ello, sus resultados. La composición granulométrica contenida en pasta de cemento, edad del hormigón, humedad, módulo de elasticidad del árido pueden dar considerables diferencias. Puesto que los procedimientos de choque sólo abarcan las propiedades de la superficie, en ambos métodos juegan un papel importante las condiciones de conservación, secado, grado de hidratación, profundidad de carbonatación, tipo de cemento, clase de encofrado y segregación. La sola enumeración de dichos factores de influencia permiten deducir que no se ha conseguido nada con la aplicación despreocupada de las normas. El campo de dispersión es tan grande en todos los procedimientos no destructivos que no es posible una valoración exacta de la resistencia del hormigón sin conocer la composición del hormigón y sin la existencia de una curva comparativa para un hormigón dado. La predicción puede mejorarse mediante el empleo de varios proce dimientos no destructivos. Lo más adecuado es, sin embargo, tomar probetas testigo, ensayarlas con destrucción y determinar con ello, en el campo de dispersión, la situación aproximada de los valores del ensayo no destructivo.

\section{BIBLIOGRAFIA}

(1) DIN 4240, "Kugelschlagprüfung von Beton mit dichtem Gefüge Ausgabe 4". 1962.

(2) Wesohe, K.: “Kritische Betrachtung der Verfahren zur zerstörungsfreien Prüfung des Betons im Bauwerk". Bau und Bauindustrie 1960, H. 1, S. 9-15.

(3) GAEDE, K.: "Die Kugelschlagprüfung von. Beton". Deutscher Ausschuß für Stahlbeton, Heft, 107, Berlín 1952.

(4) Comité Européen du Béton (CEB). "Empfehlungen zur Berechnung und Ausführung von Stahlbetonbauwerken". Entwurf 1. 1966

(5) WEIGLER, H. und KERN, E.: "Uber die Anwendungsmöglichkeiten des Ultraschallverfahrens zur Beurteilung der Betongüte”. Betonstein-Zeitung 31 (1965), H. 5, S. 279-285.

(6) Coune, A.: "Essais non destructifs du béton sur chatier, RILEM-Ausschuß". Zerstörungsfreie Prüfung, Sitzung Aachen 1966

(7) Wesche, K. und MANNs, W.: "Betone aus Sulfathüttenzement in höherem Alter Deutscher AusschuB für Stahlbeton", Heft 186, Berlín 1966.

(8) Manns, W. und Schatz, O.: "Uber die Beeinflüssung der Festgkeit von Zementmörteln durch Karbonatisation". Betonstein-Zeitung 33 (1967), H. 5.

(9) MANNS, W. und SASSE, H. R.: "Uber die Auswertung der Kugelschlagprüfung bei Beton aus Sonderzementen". Beton 16 (1966), Heft 2, S. 63-67.

(10) GaEde, K. und Schmid, E.: "Rückprallprüfung von Beton mit dichtem Gefüge Deutscher Ausschuß für Stahlbeton”, Heft 158, Berlín 1964.

(11) Campus, F., Dutron, R. und Coune, A.: "Contrôle de la qualité du béton en laboratoire et sur chantier". Centre scientifique et technique de la construction", Compte rendu de recherche no. 3 , Brüssel, 1964.

(12) Weigler, H., Siemers, H. und Spitzner, J.: "Zur nachträglichen Bestimmung der Betondruckfestigkeit”. Betonstein-Zeitung 32 (1966), H. 3.

(13) Wesche, K.: "Vergleich von Ergebnissen der Schlagprüfung an Beton im Bauwerk mit der Norm DIN 4 240”. RILEN-Ausschuss Zerstörungsfreie Prüfung von Beton, Sitzung Bukarest 1964. 
(14) “CUR-Rapport 18, Niet-destructief onderzoek van beton, deel II”. Commissie voor Uitvoering van Research, Niederlande.

(15) FACAOARU, I.: “L'expérience de l'application des normes roumaines provisoires pour la determination de la résistance du béton à l'aide du scléromètre Schmidt RILEM-Ausschuß" Zerstörungsfreie Prüfung von Beton, Sitzung Bukarest 1964.

(16) “CUR-Rapport 33, Niet-destructief onderzoek van beton, deel III”. Commissie voor Uitvoering van Research, Niederlande.

(17) Facaoaru, I., Dumitrescu, I. und Constantinescu, L.: "Concrete strength determination by non-destructive combined methods”. RILEM-Auschuß Zerstörungsfreie Prüfung, Sitzung Aachen 1966.

(18) FACAOARU, I.: “L'espérience de l'application des normes roumaines provisoires pour l'essai du béton à l'aide des ultrasons". RILEM-Ausschuß Zerstörungsfrei Prüfung von Beton, Bitzung Bukarest 1964.

(19) Skramtajew, B. G. und LeszcinskiJ, M. J.: "Complex methods of nondestructive tests of concrete in constructions and structural works". RILEM-Bulletin N.o 30, März 1966.

(20) Brunarski, L.: "Gleichzeitige Anwendung verschiedener zerströrungsfreier Prüfmethoden zur Gütekontrolle des Betons". Wissenschaftliche Zeitschrift der Hochschule für Bauwesen Leipzig, Sonderdruck 1963.

(21) Ciganek, M. und Sedlak, I.: "Statistische Veränderlichkeit der Betongüte bei fertiggestellten Bauten nach den Messergebnissen mittels Ultraschallverfahren". Wissenschaftliche Zeitschrift der Hochschule für Bauwesen Leipzig, Sonderdruk 1964.

(22) Slachta, E.: "Messungen der Qualität des Betons mit dynamischen Methoden", Wissenschaftliche Zeitschrift der Hochschule für Bauwesen Leipzig, Sonderdruck 1963. 